\title{
1 Is too much personal dread stifling alternative pathways to 2 improving urban water security?
}

3 Anna Kosovac ${ }^{1,2}$, Brian Davidson ${ }^{2}$

$4{ }^{1}$ Connected Cities Lab, Faculty of Architecture, Building and Planning, The University of

5 Melbourne, Parkville Victoria Australia 3010

$6 \quad{ }^{2}$ Faculty of Veterinary and Agricultural Sciences, The University of Melbourne, Australia

$7 \quad$ All enquiries to: anna.kosovac@unimelb.edu.au

\section{Abstract}

9 Despite an ongoing dire prognosis of the state of water resources, water practitioners maintain their traditional approaches to water planning. Alternative water projects to those that are considered 'business-as-usual' are not contemplated despite the threats posed by increasing urbanisation and climate change. Previous studies in psychological perceptions of risk in other fields have found that the personal feelings of risk practitioners, particularly feelings of dread, have had a significant impact on risk perceptions, an element known to be affecting decision-making of an individual. Could a similar trend exist in the water sector? We consider the decision-making process of 77 water practitioners in Melbourne Australia, to determine their personal biases and attitudes towards these alternative water pathways. In particular, this study assesses the impact of cognitive bias on reported risk scores in the water sector. Utilising pre-validated risk psychology survey methodology (Slovic et al, 1985), psychometric testing was conducted to determine the influences that guide their personal risk perceptions, and in turn, their decision-making processes. It was concluded that 'Dread' plays a key role in the variation of risk scores between the participants that were evaluated. Furthermore, variables such as 'Fear of the Unknown' and 'Dread related to perceived fatal risk' where also found to be statistically significant factors in the link between risk scores and cognitive bias. These findings are critical in water planning, as a feeling of dread may be driving up risk scores, thus reducing the chances of establishing alternative water projects. 


\section{Introduction}

Cities are increasingly dealing with the effects of anthropogenic climate change and rising

urbanisation; the former reduces the supply of water resources, the latter results in an increase in water demand in urban areas. In Australia, despite a distinct divide between rural and urban water systems, environmental water use, farming and city demands all vie for a share of the declining water resource pool. Looking globally, with water resources constrained, and demand peaking, calls are being made to find and evaluate alternative options to solve the problem of water security (Romano and Akhmouch, 2019). As new or unfamiliar projects and innovations in the water sector are not being established some concerns have been raised regarding the way water resources are being managed.

In this paper, we consider the way in which decisions are being evaluated in a water-strained environment, focusing on the role that personal risk perceptions of decision-makers play in the allocation of public funds. Risk aversion has previously been mentioned in the context of water planning and yet has not been explored via psychometric testing detail (West et al., 2017, Gober et al., 2013, Dobbie and Brown, 2014). Within this research, we seek to address this gap, and in doing so, provide an insight into the psychological theory of risk and how the underlying personal biases of those who evaluate water sector projects seep into public-sector decision-making.

Those who assess the risks of water infrastructure from four different authorities in Melbourne, Australia, were selected as a case study for this research. Water security in Melbourne has remained of high public interest, due to the long periods of drought that have had an impact upon the water management of the region, a discussion that has been at the forefront again in mid-2019 (Davis and Doyle, 2019, Barbour, 2019). Stream flows in Victoria, Australia are projected to decrease between by 24 and $87 \%$, with the worst-case scenario reporting stream flows to be $78 \%$ worse than the Millennium Drought, which occurred in South Eastern Australia between 1997 and 2009 (Fiddes and

52 Timbal, 2017). A further pressing issue in Melbourne is the increase in urbanization, a phenomenon that has ultimately resulted in the most striking impact upon water shortages increasing the strain on 
infrastructure (Short et al., 2010). And this is not an issue that will subside in the near future.

Urbanisation is expected to intensify, with Melbourne projected to increase from $77 \%$ of Victoria's population to $79 \%$ by 2027 (Australian Bureau of Statistics, 2018), and become the largest city in Australia. This trend of increasing population is not unusual for water strained cities globally (Domene and Saurí, 2006, Mustafa et al., 2016). In 1900, only ten percent of the world's people lived in cities, by 2000, this was over 50 percent (Luke, 2006). It is predicted that by 2050,67 percent of the projected ten billion global population will be living in cities (Luke, 2006). This will place a large strain on public infrastructure and in particular, on water resources. As water issues become evermore concerning, the need for new approaches to dealing with supply and demand issues will increase. Innovative projects exist, such as stormwater harvesting schemes, sponge cities, and decentralised water recycling plants, all promoted heavily by private industry. However, the take-up of these alternative approaches is relatively low within the water utilities themselves, which some authors posit could be due to risk aversion (West et al., 2016, Gober et al., 2013). This begs the question of why risk aversion is present. In our previous paper, (Kosovac et al., 2019) we argued that in providing quantified justification for options through formal 'objective' assessments of risk assessments, water practitioners could not be devoid of subjective bias. In this paper an attempt is made to understand this dynamic further. We ask whether the psychological affiliations of a risk assessor could affect these scores. Furthermore, could the underlying personal psychological biases behind environmental decision-making in water planning determine the scores assessors provided? To evaluate these questions psychometric paradigm testing was conducted on 77 risk assessors drawn from the four water authorities that govern the supply of water in Melbourne Australia. A Principal Component Analysis was undertaken on these results to reduce the factors when regressing against the risk scores provided through original risk assessments.

\section{Risk, risk perceptions and the psychology of risk}




\subsection{Why Risk?}

Public infrastructure, including water and sewage services, is essential to the efficient functioning of urban areas. This infrastructure provides the resources necessary to support urban economies, environments and societies. Decisions surrounding their design and maintenance involve the formal assessment of risk by experts ${ }^{1}$. Risk assessments form a required and important part of decisionmaking in the public sector, playing a key role in business processes for the past 50 years with little to no overhauling of practices during this period (Council of Standards Australia, 2009, International Organization for Standardization, 2009). Furthermore, risk assessments are trusted and seen as a source of truth by practitioners making decisions using public funds. When discussing risk, especially in a business setting, it is not unusual that it is seen as an objective and measurable value (Kosovac et al., 2019), a theme on which existing risk processes and standards have been predicated. Risk is often seen as the combination of the likelihood and corresponding consequence of a particular hazard, and in its simplicity ignores much of the broad study in risk that also considers cultural and psychological elements (Kosovac et al., 2017, Kosovac et al., 2019). Many analysts have turned a critical eye to risk assessments in the literature, but as yet have not considered the water sector in depth. This is surprising, especially since water is a politically contentious global issue.

\subsection{The Psychology of Risk Perceptions}

Slovic (1993), a key proponent of the psychological risk approach, recognised that 'danger is real, but risk is socially constructed' (Slovic, 1993). The Psychological theory of risk, also called Cognitive Bias theory, takes a micro-level approach to understanding risk through focusing on the individual decision-maker and how they form their judgments, a theory heavily based on their underlying beliefs and experiences. Risk perception is considered to be closely tied to an individual's personal

\footnotetext{
${ }^{1}$ The word 'expert' is used in this paper to refer to a person with specialised knowledge in a particular area, in particular those who have mastered certain skills they utilise in their careers. It is used interchangeably with 'professional'.
} 
perspective through linking risk choices to their own values and psychology (Fischhoff et al., 1978).

102 These experiences create a personal prism through which the individual assesses risks, ultimately

103 forming their perceptions (Slovic et al., 1985, Slovic, 1993). Through these personal perceptions, the

104 focus is predominantly on decision-making biases with a strong emphasis on the intuitive processing of uncertainty. In this way, the Psychological theory promotes the importance of personal and contextual variables in the individual assignation of risk to certain factors over others.

The Psychological theory of risk takes into account the role of emotions in decision making, an area that has only recently been seriously considered by sociologists analysing risk, and largely ignored by other areas of the field (Zinn, 2008). The impact of past emotional experiences is used to form judgments based on anticipated emotion, and has been shown to be important in making reasonable and sound decisions (Baumeister et al., 2007), an idea that is not congruent with the sentiment felt by rationalists. If a strong negative emotional connection to a risk exists, it can affect an individual's capacity to identify the probabilities of the scenarios, focusing instead on the outcomes that evoke a sense of dread (the affect heuristic). An emotional feeling of dread is an important factor in propelling an individual to act on a risk, risks that are often being associated with outcomes that affect one personally, have a detrimental effect on future generations or present a catastrophic widespread threat to a large number of people (Baumeister et al., 2007, Gigerenzer, 2004, Slovic et al., 1985). Like most theories, the psychological paradigm is not without its critics. Lupton (2013) argues that there are still inconsistent epistemological underpinnings to the psychological concept of risk, with some scholars viewing risk as 'real' and 'actual', while others contend that human cannot possibly see the 'real' risk, but only their 'perception' of it. This is blurred even further by the consistent notion of studies comparing expert views (seen as 'accurate') to that of laypeople. Douglas (2010) also asserts that the psychometric paradigm ignores many elements of meaning and behaviours in social systems. Despite these shortcomings and criticisms, the psychometric paradigm is still arguably the most influential model in risk analysis, and as such is utilised further in this study (Siegrist et al., 2005).

\subsection{Risk Perception in Democracy: Experts vs laypeople}


127 The importance of understanding public perception of risk associated with urban infrastructure

128 projects has gained prominence over the past three decades. This is, in part, due to public and political

129 opposition to project proposals, which ultimately led to the abandonment of plans in some cases. A

130 good example of this was the opposition to the proposed potable recycled water systems in

131 Toowoomba, Australia (Hurlimann and Dolnicar, 2010) and San Diego, USA in the 1990s (Mills et

132 al., 2004). A more recent example is the case of the chlorination of water in the Cook Islands

133 (Aualiitia, 2019).

134 Extensive research has been undertaken on the differences in risk perceptions between laypeople and 135 experts (Shrader-Frechette, 1991), a field of study which expanded in the 1980s and continues to 136 provide insights into understanding risk perceptions, a particularly pertinent consideration in an 137 environment in which participatory democracy is encouraged and the gap between experts and 138 laypeople is arguably wider than ever (Nichols, 2017). When comparing public risk perceptions to that of experts, Slovic et al (1983) showed that laypeople surveyed generally ranked nuclear energy

140 high in risk because of the sense of dread associated with the effects of a negative radioactive fallout.

141 In comparison, laypeople ranked the risk of driving a car very low, despite the statistical chance of 142 being involved in a car accident being far higher than being caught up in a nuclear one (Slovic et al., 143 1985). Experts conversely ranked driving a car as significantly higher risk than that surrounding 144 nuclear power, which the authors suggest is based on an objective understanding of the safety of nuclear energy. Thus, they conclude that the dread or familiarity factor (among others) for experts is 146 dissimilar to that of the layperson.

147 A reflection of this is shown in a study by Schlosberg et al (2017) in Melbourne, Australia, drawing a clear distinction between climate change discourses undertaken by government authorities and the public. In considering climate change adaptation, local government bodies used words like 'risk', 'water', 'control', 'event' and 'management'. In contrast, the authors found that community groups used language that focused more on the impacts of basic needs, such as 'food', 'community', 152 'people', 'energy', 'water' and 'local' (Schlosberg et al., 2017). Guy et al. (2014) instead questions whether a distinction between the knowledge-based of two groups causes a problem; that the experts 
rely on their extensive understanding of the subject matter to form their risk perceptions, whereas laypeople must rely on their limited knowledge and the risk perceptions of those they trust (Siegrist and Cvetkovich, 2000), the result of which are alternative risk perceptions.

This difference in risk perceptions evident between laypeople and experts becomes a challenge when the questions of public policy and public spending is discussed. Prior to the 1960s, expert assessments were generally accepted by the public, with far less scrutiny than they are today (Nichols, 2017). As such, public consultations and public opinion polling did not carry the relevance it currently does, and consequently, forms an integral part of project planning. Schon (1995) argues that the loss of faith in professional judgement occurred between 1963 and 1981, due in part to the unintended side effects of new technologies and the conflicting recommendations within professional fields itself. The consistent debunking of professional advice and theories proved to be a large factor in the increasing distrust of professional experts (Schon, 1995) (Nichols, 2017) which ultimately provided an unexpected side effect: the increase in public distrust has been transposed to now affect the public acceptance of risk assessments conducted by these experts (Slovic, 1993, Siegrist et al., 2000, Siegrist, 2019). Nevertheless, with the authority afforded them, experts make decisions on behalf of many. Therefore, these decisions, especially in a participatory democracy, should be (and often are) understood and scrutinised.

\section{Research Design}

In seeking to understand the underlying decision-making of water practitioners, we undertook a risk psychometric survey on this cohort, in order to compare against risk assessment scores they used to justify spending across differing water projects. Regression techniques can be used to evaluate the association between an individual's risk score and a range of the psychological factors that are posited to affect it.

These cognitive biases were tested through a set of questions addressed to 77 participants, drawn from the four water authorities in Melbourne, Australia. The majority (38\%) of the participants were aged between 36 and 45 years, with $27 \%$ between 26 to 35 years, and $23 \%$ between 46 and 55 years of age. The majority of respondents had identified as male (74\%) which is broadly representative of the 
highly-male dominated field. Of the respondents, $42 \%$ identified that they were either at team manager level or divisional manager level of authority within their organisation. Each participant was provided with descriptions of three fictional water projects:

- Using recycled water for potable water uses (Project A);

- a new radiation-based treatment approach (Project B); and

- the removal of fluoride dosing from the water treatment process (Project C).

Participants were asked to use their own organisational risk-matrix tool, an approach utilised widely throughout the water industry, in assigning risk scores. The risk matrix quantifies a 'risk likelihood' and 'risk consequence' score for assessment both quantifications were assessed between 1 and 5 (Kosovac, Davidson and Malano, 2019). The product of these two scores provides the final risk score which is reported in internal business cases, ranging from 1 to 25 . This final score was used to capture and quantify risks in the proposed water projects. It should be acknowledged that limitations exist in the use of organisational risk matrices, as they may produce variance that is not controlled. The approaches between the organisations were extremely similar, but there were minor variations.

Participants were provided with a number of psychological affiliation questions related to each project's perceived risks. The pre-validated survey questions were derived from a similar study by Slovic et al (1985). These questions can be interpreted to describe the attitudes participants have to risk. The questions include:

- Voluntariness of Risk - whether people who are faced with this risk, do so voluntarily;

- Immediacy of Effect - whether death occurs immediately, or whether it is delayed (for example, radiation);

- Knowledge about Risk (to those exposed) - to what extent people who are exposed to risk, know about the risk;

- Knowledge about Risk (to Scientists) - to what extent does the assessor believe that experts understand the risks;

- Control over Risk - whether those exposed to the risk can effectively avoid death or injury through choice, and personal skill;

- Newness - determines how new the assessor feels this risk is (as opposed to old and familiar);

- Chronic-Catastrophic - whether the risk kills people one at a time or all at once (assuming that death is an outcome);

- Common - Dread - assesses how much dread is associated with the risk;

- Severity of Consequence - the likelihood of a risk being fatal; and

- Unfairness - assessing how fair the risk seems to the assessor (does it affect all people fairly). (This was not assessed in the original 1985 study, and was introduced at a later date.) 
216 Participants were prompted to highlight their responses to these questions on a 7-point Likert scale.

217 The responses to these questions are compared against the individual's respective risk scores for the 218 three pre-defined fictional alternative water projects.

219 The key difference in this study to others (such as Slovic (1992) and Fischhoff et al. (1978)) is the 220 direct comparison made between the psychological risk perception determinants and the quantitative risk scores of each individual. In particular, the aim is to determine whether there is a risk attribute that is linked to higher risk scores. This could result in the one overarching risk attribute, or a combination of risk attributes, that tends to indicate higher or lower risk scores, providing an explanatory and predictive tool in the understanding of risk. Thus, the aim is to determine to what extent a particular psychological affiliation produces a higher risk score in the water industry. The scores were recorded and analysed using IBM SPSS.

There is a need to determine whether there is any correlation between the responses to the ten psychological attributes and the risk scores provided by each respondent for each project. Two forms of regression analysis can be undertaken: the individual risk attributes on corresponding risk scores, and a grouped variable (combination of a number of variables using a Principal Component Analysis) on risk scores. Principal Component Analysis (PCA) is used to determine whether a combination of variables may better describe psychological affiliations of participants than the individual attributes themselves. It applies a vector space transformation to lower the number of variables to those that are possibly correlated, thus creating a new factor variable out of individual attributes. The aim of the analysis is to find a principal component (a combination of the tested variables) that explains the highest amount of variation in risk scores

\section{Results}

4.1 Reducing the number of variables: Principal Component Analysis

As the individual attributes themselves did not provide overly promising results, it must be asked whether a combination of the variables could instead provide a better model fit. 
241 Each principal component highlights the extent to which it explains the variation in the data, followed

242 by other principal components, until the majority of the data is explained. The total variance

243 explained by the first five factors for Principal Component 1 is shown in Table 2, for projects A, B

244 and C.

Table 1 Principal Component Analysis, Total Variance Explained

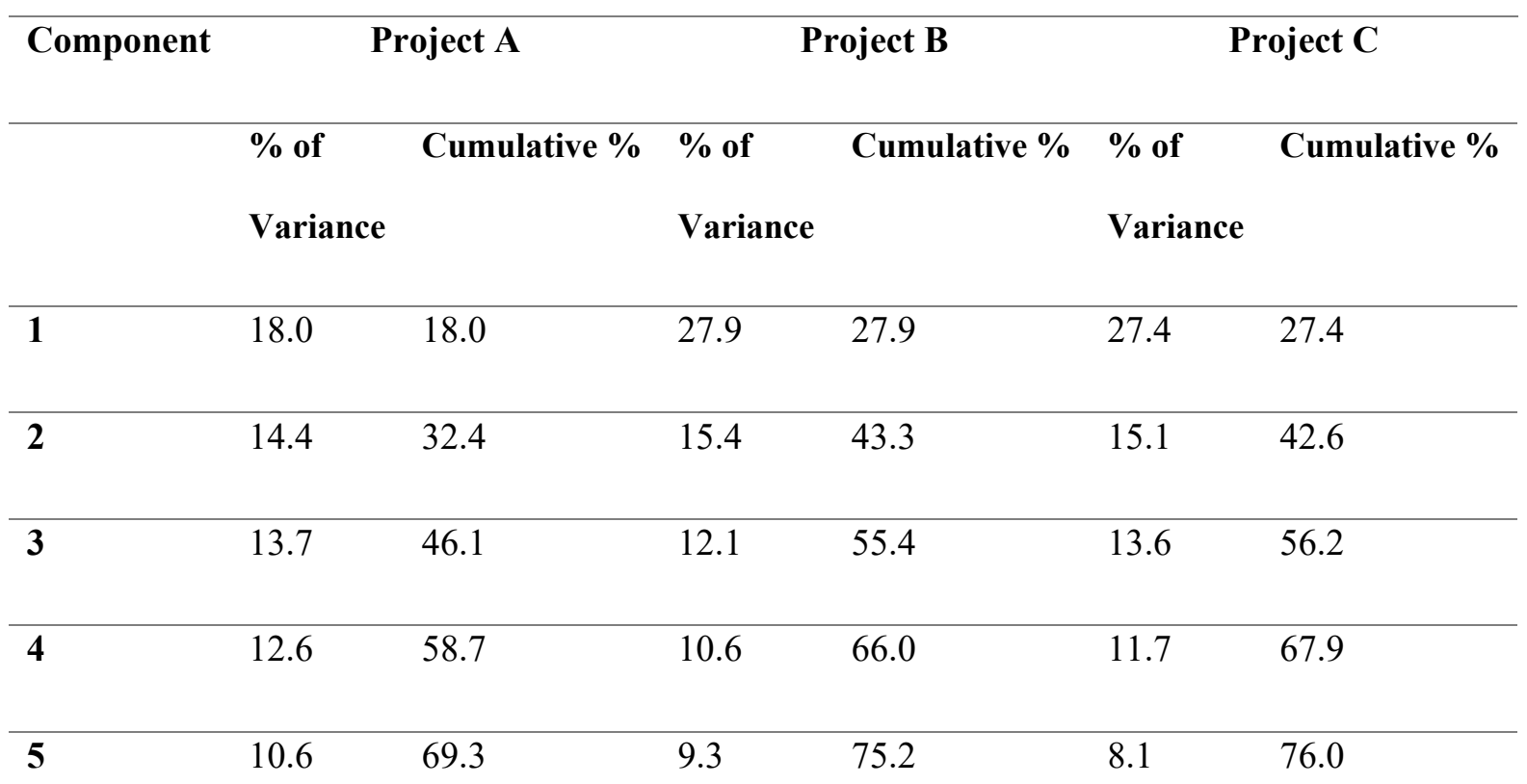

It should be noted that similar results from Projects B and C were obtained, approximately threequarters of the variation in results being explained by the first five principal components. Project A, although a lower cumulative explanation (at $46 \%$ for the first three attributes), should still be included in further analysis, as it does reflect a sizable proportion of the explanation. The first three attributes are taken for each new Principal Component Analysis variable, thus explaining approximately 50\% of

254 the variation in risk scores. Knowing this provides the opportunity to understand whether there are meaningful results that can be gleaned from the grouping of the attributes. 


\subsection{Principal Component Analysis 1: Dread Related to Perceived Fatal Risk}

257 Through conducting the Principal Component Analysis, the three highest acting attributes are incorporated and used for a further regression analysis with risk scores. In Figure 1 the attributes that have been combined to create the first new variable are shown. Does it provide a meaningful measure that will help to explain the variation in risk scores? Principal Component number 2 (not shown in Table 1) is not included in any further analysis as the explanation of variation falls drastically to only approximately $15 \%$ for all projects, cumulatively across the five attributes. It would also result in six new variables, two for each project, which is too many to meaningfully conduct an analysis, thus rendering the variable reducing exercise redundant.

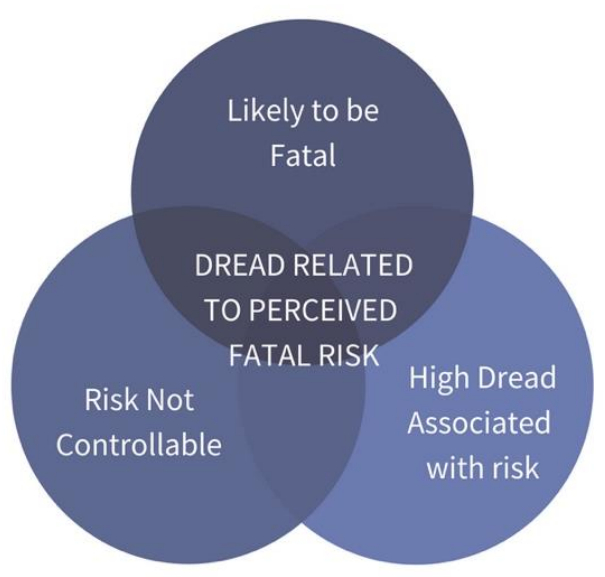

It is vital that this analysis ensures that the Principal Component Analysis grouping of the attributes provides meaningful explanation of the data and therefore whether the attributes can be linked in some way to encompass an overarching theme can be questioned. The highest acting attributes for Project A (using recycled water for potable system) were 'likely to be fatal', 'risk not controllable' and 'high dread associated with the risk' (refer to Figure 1). In considering how these elements can 
meaningfully be captured by the new variable, can be described as the high sense of dread likely to result from a risk that is perceived to be fatal and uncontrollable.

\subsection{Principle Component Analysis 2: Fear of the Unknown}

278 Project B, related to the use of radiation in the treatment of water, provided a principal component variable that included the risk attributes: Risk Known by those Exposed, Risk Known by Science, and Newness of Risk. This grouping exhibits a key theme in the 'knowledge' based element of risk perceptions. These factors were grouped into one new variable, titled 'Fear of the unknown' (refer to Figure 2) as it captures the knowledge of the risk by those who are exposed to it, while also highlighting whether the risk is known to experts at all. Interestingly, the third highest acting attribute is the 'newness' of the risk. If the risk is unknown to both science as well as to those exposed, it makes sense that it could also be considered 'new' or 'novel'.

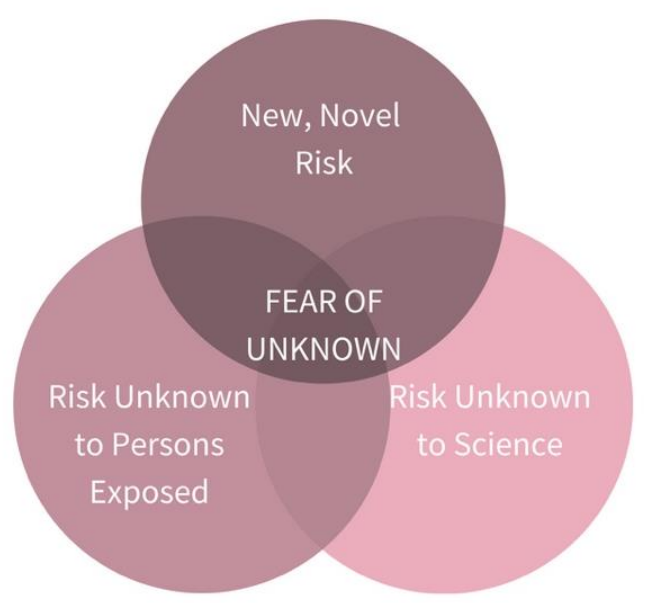

In describing this attribute grouping, the knowledge-based elements are captured, as well as the unacquainted relationship between risk assessor and risk. When testing this new variable against the 
entire risk project scores, the $\mathrm{R}^{2}$ score was $0.05,(\mathrm{P}=0.00)$. This indicates a low-level explanation of the variation in the risk scores across the three projects, and across respondents.

\subsection{What does the Principal Component Analysis tell us?}

Project A describes a scenario where recycled water is provided in the potable supply. Therefore, it is not surprising that elements such as 'risk known to those exposed is high', as well as perceived 'fairness of the risk' and 'risk control' feature in this analysis. All of these factors relate to the person who is drinking the recycled water, perhaps referring to a low knowledge of the risks personally experienced, and the lack of choice regarding whether they are provided with recycled water in their potable water mains. In this scenario, then, it is not surprising* that these factors are grouped together. Projects $\mathrm{B}$ and $\mathrm{C}$ have very similar principal attributes acting on their first principal component. The risk is known to persons exposed, science, as is the level of control of the risk and how new or unfamiliar the risk is to those exposed. The factors of feeling of dread toward risk and risk of fatality also feature highly. Project B involves the use of a new radiation process in the treatment of water. The findings, using psychometric testing on radiation treatments, are similar to those found by others (Fischhoff et al., 1983). A linear regression analysis was performed on the two new risk variables: "Dread Related to Perceived Fatal Risk", and "Fear of the Unknown", (see Table 2). The regression was undertaken across all projects, as well as in each project separately.

\begin{tabular}{lllll}
\hline New Risk Variables & All Projects & Project A & Project B (Use of & Project C \\
& Combined & (Recycled Water & radiation in the & (Removing \\
& to Potable & treatment of & Fluoride from \\
& Water) & potable water) & potable water \\
& & & supply)
\end{tabular}




\begin{tabular}{lllll}
\hline Dread related to & $\mathrm{R}^{2}=0.10^{*}$ & $\mathrm{R}^{2}=0.02$ & $\mathrm{R}^{2}=0.24^{*}=0.01$
\end{tabular}

\section{Perceived Fatal Risk}

Fear of the Unknown $\quad \mathrm{R}^{2}=0.05^{*} \quad \mathrm{R}^{2}=0.02 \quad \mathrm{R}^{2}=0.16^{*} \quad \mathrm{R}^{2}=0.01$

Testing Projects $\mathrm{A}$ and $\mathrm{C}$ resulted in a $\rho$ value that was higher than 0.05 , indicating that the null

hypothesis cannot be rejected: it cannot be stated that the 'fear of the unknown' variable is statistically significant in predicting the variation of risk scores between respondents. However, interestingly, running a regression against project B 'fear of the unknown' variable and its corresponding risk score, resulted in $\mathrm{R}^{2}=0.16$. This result could be rather telling and is not statistically insignificant. Thus, the variable could explain an element of how risk is perceived psychologically by risk assessors in the water sector. Furthermore, the dread related to the perceived fatal risk variable explained $24 \%$ of the variation in the scores for Project B, a reasonably high goodness-of-fit coefficient.

\section{Discussion}

\subsection{Dread a factor across all projects tested}

'Perceived dread due to fatal risk' considers the effect of the risk assessor imagining a scenario within the project that results in a fatality, and therefore conjures up feelings of dread. Unsurprisingly, with this feeling also comes a heightened sense of perceived risk, and higher risk scores. However, this only had a significant effect when tested on Project B: the use of radiation in the treatment of water. Explaining $24 \%$ of the variation in the risk score, this variable explains a sizable aspect of the psychological affiliations to the risk score. It should be noted that this result needs to be interpreted this in the context of the radiation theme of the tested project, which is notably different to the intent of projects A and C. This difference has been noted by a number of studies in this area, highlighting that risk perceptions of radiation and nuclear-technology are high compared to other activities such as driving a car, or smoking, which tend to carry far higher mortality rates (Shrader-Frechette, 1991). 
with this type of technology (Pahner, 1976). Evoking affect (and availability) heuristics, the devastation from nuclear accidents such as Chernobyl and Three Mile Island still carry vividly in the minds of people, especially in the context of Australia, where only one nuclear reactor currently exists. This cultural aversion to nuclear technology could account for the higher uncertainty, and a higher perceived probability of fatalities mentally evoked, suggesting the availability heuristic in deeming this risk of higher calibre than otherwise.

Project B proposes a process that is unfamiliar to water professionals, a factor highlighted by Principal Component Analysis variable 'fear of the unknown'. Projects A and C are based on altering the water supply in a way that is not unusual or unimaginable in the water sector, despite having never been undertaken. Whereas, the lack of knowledge and awareness of new technologies in radiation treatment could be said to provide a level of healthy scepticism in rating its riskiness. This is suggested by the exhibited influence that 'fear of the unknown', a knowledge-based factor, has on the risk assessor's score.

'Fear of the unknown' is made up of knowledge-based attributes such as the 'newness' and 'unfamiliarity' of the project, in combination with a clear understanding of the risk by both those exposed and science. This amalgamation of psychological attributes provides an insight into explaining approximately $5 \%$ of the variation in the risk scores across all projects. This rises to $16 \%$ in the case of Project B, the use of radiation in the treatment of water suggesting that the risk score could be then guided by a perceived lack of knowledge by both science and those exposed. Although other projects have been rated as 'extreme' by respondents in their risk ratings, none were as clearly linked to the psychological attribute of 'fear of the unknown' quite so starkly as Project B.

Observing the qualitative responses provided in project B provides some insight into the issue (authors, 2017). Compared to Projects A and C, distrust or questioning of current research seems to

360 feature highly in Project B. Previous research in heuristics sheds some light on these findings.

361 Heuristics states the importance of relying on trust in expert knowledge in decision-making (Siegrist and Cvetkovich, 2000). As individuals cannot possibly know all there is to know about all levels of 
technology, it is therefore important to rely on others trusted sources to provide guidance in areas individuals have inadequate knowledge (Slovic, 1993). Therefore, when new technologies arise, as in the case of innovations such as what is proposed in Project B, the importance of trust in the researchers that have undertaken the studies is pertinent in guiding the risk perception of water practitioners in this study (Siegrist and Cvetkovich, 2000). The importance of trusting those who provide that knowledge is very high in areas of uncertainty. When exploring new or innovative projects the impact of trust or reliance upon other experts cannot be understated, as is shown in this work.

While projects $\mathrm{A}$ and $\mathrm{C}$ did not highlight a significant link to the Principal Component Analysis variables, they were nevertheless found to have a significant link to one of the risk attributes: the 'feeling of dread'. The higher the sense of dread surrounding the risk, the higher the risk score given. This explained approximately $9 \%$ of the variation in the risk scores, which, although not high, is still notable for a psychometric study (Slovic et al., 1985). None of the other risk attributes were found to be statistically significant in explaining the risk scores. In considering previous studies in the psychology of risk perceptions, dread would appear frequently as a significant risk attribute in risk perceptions (Gigerenzer, 2004, Slovic et al., 1981). The difference is that within these studies risk matrix scores were not compared to psychological risk attributes. Rather, these attributes were measured on a dimensionless scale to compare them to other activities. It is helpful to know that in this study we provide an insight into the risk scores themselves, which has practical and tangible outcomes in a business process.

What are the implications of a feeling of dread on scoring of future projects? It can be concluded from the findings of this research that the more the individual visualizes a scenario that evokes a feeling of dread (and therefore the affect heuristic), the higher the risk score. This is particularly helpful when considering that one of the two inputs into determining the risk score or rating is the 'consequence' of the project. The determination of 'consequence' heavily relies upon the risk assessor imagining scenarios on which to base their rating. The consequence may well be heavily weighted towards images enacted and created within the individual's mind. The worse the perceived imagery, the worse 
the consequence, thus the higher feeling of dread attached to it. In addition to this, the lower the consequence, the less likely that one would experience a high feeling of dread. Unsurprisingly, the worse the perceived consequence, the higher the feeling of dread. In this way, it can be posited that the internal imaginings of the risk assessor, in particular whether they believe a project will result in a catastrophic outcome, points to whether project attracts a high-risk rating. The dread factor could then highlight a key element in understanding how consequence is scored in the risk matrix, affecting and influencing the feeling of dread in assigning this score. A limitation exists in this study through not collecting separate consequence and likelihood scores on which to conduct separate regression analysis. We nevertheless posit that as dread is 'imagined' in these contexts, water professionals carry through their imagined fears into the assessment of the risk.

\section{Conclusion: Is personal dread suppressing sustainable water planning?}

The impact of a perceived sense of dread in higher risk scores carries ominous implications for the future of water planning. It was found that those that may internally catastrophize an outcome of a project, thus evoking a sense of dread, may result in developing higher risk ratings than the average risk assessor. The effect of 'dread' and to some extent, 'fear of the unknown' leads to personal discrimination against original approaches to solving future water issues, instead opting for tried and true options. These questions lead back to the original sentiment that the water sector is slow to take on innovative projects and methods, and even stifles them. As urbanization and general increases in population strain current water infrastructure, the personal risk perceptions of the assessors themselves highlight an important aspect in understanding funding allocations for future water solutions. This also leads to questions surrounding of the current 'objectivity' of public fund allocations in delivering and planning for the future city.

These types of evidence-based changes can have a substantial impact upon water decisions in the future and may allow for a greater rate of uptake of projects that are unusual and innovative in nature, even though they are designed to counter the predicted increased water demand of users. Adaptation measures in the face of a changing climate are openly discussed, however alternatives to business-asusual face the risk perceptions of current assessors. Ultimately, as Frank Fischer succinctly puts it, 
417 some risk-taking should “... be seen as necessary for successful technological change... as well as the 418 overall resiliency and health of modern society" (Fischer, 1991). Through increasing awareness of 419 biases, effective planning approaches can be enacted without the impact of personal affiliations 420 curbing uptake of technological developments that can aid future water shortage issues.

421 Acknowledgements: Thank you to Professor Hector Malano for providing feedback and comment on the study. 422 Funding: This work was supported by Yarra Valley Water and the University of Melbourne 


\section{References}

Cook Islands Water, 2019. Directed by AUALIITIA, T.: Australian Broadcasting Corporation.

AUSTRALIAN BUREAU OF STATISTICS. 2018. "Capital Cities and Rest of State/Territory Regions" [Online]. Available: https://www.abs.gov.au/ausstats/abs@.nsf/0/5A9C0859C5F50C30CA25718C0015182F? [Accessed 25 July 2019].

BARBOUR, L. 2019. Country towns close to reaching 'day zero', as water supplies dry up in the drought. $A B C$ News, July 23

BAUMEISTER, R. F., DEWALL, N. \& ZHANG, L. 2007. Do Emotions Improve or Hinder the Decision Making Process? In: VOHS, K. D., BAUMEISTER, R. F. \& LOEWENSTEIN, G. F. (eds.) Do Emotions Help or Hurt Decision making: a hedgefoxian perspective. New York: Russell Sage Foundation.

COUNCIL OF STANDARDS AUSTRALIA 2009. Risk Management - Principles and Guidelines. Sydney: Standards Australia.

DAVIS, J. \& DOYLE, K. 2019. How climate change is affecting what we grow and eat. ABC News, July 17.

DOBBIE, M. F. \& BROWN, R. R. 2014. A Framework for Understanding Risk Perception, Explored from the Perspective of the Water Practitioner. Risk Analysis, 34, 294-308.

DOMENE, E. \& SAURÍ, D. 2006. Urbanisation and Water Consumption: Influencing Factors in the Metropolitan Region of Barcelona. Urban Studies, 43, 1605-1623.

DOUGLAS, M. 2010. Risk acceptability according to the social sciences, London, Routledge.

FIDDES, S. \& TIMBAL, B. 2017. Future impacts of climate change on streamflows across Victoria, Australia: making use of statistical downscaling. Climate Research, 71, 219-236.

FISCHER, F. 1991. Risk assessment and environmental crisis: toward an integration of science and participation. Industrial Crisis Quarterly, 5, 113-132.

FISCHHOFF, B., SLOVIC, P. \& LICHTENSTEIN, S. 1983. "The Public" Vs. "The Experts": Perceived Vs. Actual Disagreements About Risks of Nuclear Power. In: COVELLO, V., FLAMM, G., RODRICKS, J. \& TARDIFF, R. (eds.) The Analysis of Actual Versus Perceived Risks. New York and London: Plenum Press.

FISCHHOFF, B., SLOVIC, P., LICHTENSTEIN, S., READ, S. \& COMBS, B. 1978. How Safe Is Safe Enough - Psychometric Study Of Attitudes Towards Technological Risks And Benefits. Policy Sciences, 9, 127-152.

GIGERENZER, G. 2004. Dread Risk, September 11, and Fatal Traffic Accidents. Psychological Science, 286.

GOBER, P., LARSON, K. L., QUAY, R., POLSKY, C., CHANG, H. \& SHANDAS, V. 2013. Why Land Planners and Water Managers Don't Talk to One Another and Why They Should! Society \& Natural Resources, 26, 356-364.

GUY, S., KASHIMA, Y., WALKER, I. \& O'NEILL, S. 2014. Investigating the effects of knowledge and ideology on climate change beliefs. European Journal of Social Psychology, 44, 421-429.

HURLIMANN, A. \& DOLNICAR, S. 2010. When public opposition defeats alternative water projects - the case of Toowoomba Australia. Water Research, 44, 287-297.

INTERNATIONAL ORGANIZATION FOR STANDARDIZATION 2009. Risk Management - Risk assessment techniques.

KOSOVAC, A., DAVIDSON, B. \& MALANO, H. 2019. Are We Objective? A Study into the Effectiveness of Risk Measurement in the Water Industry. Sustainability, 11, 1279.

KOSOVAC, A., HURLIMANN, A. \& DAVIDSON, B. 2017. Water Experts' Perception of Risk for New and Unfamiliar Water Projects. Water (20734441), 9, 1.

LUKE, T. 2006. 'Global Cities' vs global cities: Rethinking Contemporary Urbanism as Public Ecology. In: BRENNER, N. \& KELL, R. (eds.) The Global Cities Reader. New York: Routledge.

LUPTON, D. 2013. Risk, New York and Oxon, Routledge. 
MILLS, R. A., KARAJEH, F. \& HULTQUIST, R. H. 2004. California's Task Force evaluation of issues confronting water reuse. Water Science And Technology: A Journal Of The International Association On Water Pollution Research, 50, 301-308.

MUSTAFA, D., ALTZ-STAMM, A. \& SCOTT, L. M. 2016. Water User Associations and the Politics of Water in Jordan. World Development, 79, 164-176.

NICHOLS, T. M. 2017. The death of expertise : the campaign against established knowledge and why it matters, New York, NY : Oxford University Press, [2017].

PAHNER, P. D. 1976. A Psychological Perspective of the Nuclear Energy Controversy. Vienna, Austria: International Institute for Applied Systems Analysis.

ROMANO, O. \& AKHMOUCH, A. 2019. Water Governance in Cities: Current Trends and Future Challenges. Water, 11, 500 .

SCHLOSBERG, D., COLLINS, L. B. \& NIEMEYER, S. 2017. Adaptation policy and community discourse: risk, vulnerability, and just transformation. Environmental Politics, 26, 413-437.

SCHON, D. A. 1995. The Reflective Practitioner: How Professionals Think in Action, England, Bookpoint Ltd.

SHORT, M. D., SCHULZ, M., ROCHETA, E. \& PETERS, G. 2010. Assessment of the Challenges in Adapting Water Resources and Infrastructure to Climate Change - Literature Review The University of New South Wales.

SHRADER-FRECHETTE, K. S. 1991. Risk and rationality : philosophical foundations for populist reforms, Berkeley University of California Press.

SIEGRIST, M. 2019. Trust and Risk Perception: A Critical Review of the Literature. Risk Analysis, 0.

SIEGRIST, M. \& CVETKOVICH, G. 2000. Perception of hazards: The role of social trust and knowledge. Risk Analysis, 20, 713-719.

SIEGRIST, M., CVETKOVICH, G. \& ROTH, C. 2000. Salient value similarity, social trust, and risk/benefit perception. Risk Analysis, 20, 353-362.

SIEGRIST, M., KELLER, C. \& KIERS, H. A. L. 2005. A New Look at the Psychometric Paradigm of Perception of Hazards. Risk Analysis, 25, 211-222.

SLOVIC, P. 1992. Perception of Risk. In: KRIMSKY, S. \& GOLDING, D. (eds.) Social Theories of Risk. Westport, CT: Praeger Publisher.

SLOVIC, P. 1993. Perceived risk, trust, and democracy. Risk Analysis: An International Journal, 675.

SLOVIC, P., FISCHHOFF, B. \& LICHTENSTEIN, S. 1981. Facts And Fears: Societal Perception Of Risk. Advances in Consumer Research, 8, 497-502.

SLOVIC, P., FISCHHOFF, B. \& LICHTENSTEIN, S. 1985. Characterising Perceived Risk. In: KATES, R. W., HOHENEMSER, C. \& KASPERSON, J. X. (eds.) Perilous Progress: Managing the Hazards of Technology. Westview.

WEST, C., KENWAY, S., HASSALL, M. \& YUAN, Z. 2016. Why do residential recycled water schemes fail? A comprehensive review of risk factors and impact on objectives. Water Research, 102, 271-281.

WEST, C., KENWAY, S., HASSALL, M. \& YUAN, Z. 2017. Expert opinion on risks to the longterm viability of residential recycled water schemes: An Australian study. Water Research, 120, 133-145.

ZINN, J. 2008. Social theories of risk and uncertainty : an introduction, Malden, MA, Blackwell Publishing. 


\section{University Library}

\section{- M M I N E R VA A gateway to Melbourne's research publications}

Minerva Access is the Institutional Repository of The University of Melbourne

Author/s:

Kosovac, A;Davidson, B

Title:

Is too much personal dread stifling alternative pathways to improving urban water security?

Date:

2020-07-01

Citation:

Kosovac, A. \& Davidson, B. (2020). Is too much personal dread stifling alternative pathways to improving urban water security?. JOURNAL OF ENVIRONMENTAL MANAGEMENT, 265, https://doi.org/10.1016/j.jenvman.2020.110496.

Persistent Link:

http://hdl.handle.net/11343/251801 